\title{
LAS REFORMAS PENDIENTES DE UNA DEMOCRACIA TODAVÍA DÉBIL
}

\author{
Alberto Aziz Nassif
}

\section{Dos mil cinco, año destinado a los spots de televisión}

L os primeros sabores de $2005^{1}$ nos sumergieron en la realidad que dejamos en 2004. El cambio continuación de los litigios pendientes y una acumulación de expectativas, en este sentido se encuentran los pendientes 'negros' de 2004: asesinatos, desafueros, linchamientos y controversias. Resulta complicado tener expectativas de cambio sobre posibles reformas legislativas dentro de un clima cada vez más polarizado.

El tono del discurso político permanece en un recrudecimiento de las confrontaciones, mientras tanto los problemas se agravan. El de seguridad pública se vuelve más complejo, y los gobiernos, independientemente de los colores partidistas, se muestran incapaces y rebasados para controlar el crimen organizado.

El contraste entre el discurso de los políticos que sólo están interesados en su promoción electoral, y el abultamiento de los problemas graves, arrojan un saldo negativo en las expectativas colocadas sobre este año.

Alber to Aziz Nassif, investigador del ciesas, México, D. F.
Las transiciones que han sido exitosas cuentan con una serie de reformas institucionales que ha dado nuevas 'reglas del juego'. En México, la ausencia de estas reformas ha dejado no sólo un gran desencanto con la democracia inicial que tenemos, también la expectativa de que después de 2006 seguiremos igual, como el burro que hace girar la noria, en el mismo lugar, pero habiendo caminado una ruta más escarpada. Así que con el juego de las tres grandes fuerzas políticas, el esquema presidencial y los gobiernos minoritarios y divididos, escenario que posiblemente se repetirá en 2006, resulta difícil encontrar buenas razones políticas para interesarse por su proceso.

\section{Democracia 'patito'}

La democracia en donde uno de los poderes puede sacarse literalmente de la manga cualquier iniciativa de ley para modificar los espacios de autonomía y afectar la resolución de procesos vigentes es una democracia marca 'patito'. Hoy en México nos encontramos en esta situación.

Cada día se hace más evidente que la lucha de fondo en este año electoral no es entre partidos y candidatos en un sentido amplio, sino entre las fuerzas que quieren llevar al país a un nuevo autoritarismo con careta 
democrática, de igual manera se estipulan las fuerzas que plantean consolidar lo logrado y realizar las modificaciones que faltan. Lo que está en peligro en los próximos años es la suerte de las instituciones. A pesar de que faltan muchas reformas y cambios institucionales, como la reforma del Estado, no se puede negar que hoy existe una división de poderes y áreas de autonomía en zonas estratégicas - información, elecciones - Sin embargo, al mismo tiempo, prevalecen graves deficiencias institucionales, intentos de restauración, incertidumbre y mucho desencanto: el gobierno dividido y minoritario no ha funcionado y el país está sometido a una confrontación permanente y a la polarización creciente.

A medida que se ha desarrollado el sexenio ha acrecentado una lucha entre las fuerzas que quieren ganar la contienda de 2006. En los últimos años los movimientos y estrategias empleados han tenido como principal objetivo una larga fase de preparación por la Presidencia de la República. Como parte de esa lucha por el poder se ha puesto en la mira cierta recomposición oportunista de ciertos espacios públicos y, por supuesto, se ha impedido la transformación de otros nudos institucionales. El diferendo suscitado entre el Poder Ejecutivo y el Poder Legislativo por el presupuesto de egresos para 2005, que fue llevado a instancias del Poder Judicial, sirve de ejemplo.

PRI y PRD ${ }^{2}$ enfrentaron a la Suprema Corte de Justicia de la Nación, scjN, porque admitió la controversia del ejecutivo y les congeló unas partidas presupuestales; se les ocurrió primero amenazar con un juicio político a los ministros de la Corte, después propusieron una iniciativa de ley para crear un tribunal constitucional que estuviera por encima de los tres poderes del Estado. En la iniciativa de ley se establecían las funciones que tendría este nuevo tribunal. El único problema es que la Corte es ya un tribunal constitucional, como lo señaló el ministro José Ramón Cossío (ElUniversal,14/I/2005).
Al existir el Instituto Federal Electoral, IFE, no se necesitó crear otro, porque simplemente eligieron un consejo a su gusto; sólo hay que recordar que en aquella ocasión fueron PAN ${ }^{3}$ y PRI. Se da una tendencia a debilitar las instituciones que pueden fortalecer y consolidar la democracia. Sólo hay que esperar la renovación del Instituto Federal de Acceso a la Información Pública, IFAI, para ver cómo, probablemente, se le desgastará con una segunda generación de comisionados al antojo de fuerzas políticas regresivas.

Esta tendencia de debilitar a las instituciones tiene su complemento en el oportunismo político de partidos y gobiernos, que provocan una degradación política. Ya no se sabe quién defiende qué. Los partidos y los gobiernos se han desdibujado. Vivimos un serio deterioro político en el país. Las pugnas dentro de los partidos generan la fuga de militantes en busca de nuevas siglas. Ya se ha empezado a generalizar el alquiler de registros partidistas como placas de circulación política. La competencia propicia el oportunismo para tener candidatos competitivos. El PRD es un residuo del PRI, así nació y así continúa. Pero el esquema se practica en todos los partidos y los ejemplos se multiplican. El modelo de partido profesional electoral es una maquinaria de mercadotecnia para 'cachar' votos y también candidatos. Se han acabado las plataformas ideológicas y las diferencias.

\section{Discursos y realidades no se 'tocan'}

Hemos llegado a la construcción de un nuevo fenómeno político: el discurso no se 'toca' con la realidad, los acontecimientos estrujan y escandalizan, las acciones se hacen sin planes establecidos; domina plenamente la coyuntura. La política ha entrado de tiempo completo a la lucha sucesoria del poder, ya se terminó la fase de sucesión adelantada en la que vivió el país los dos años anteriores. En este extraño contexto se trataron de impulsar reformas legislativas. 
Los partidos se preparan para 2006; los grupos y liderazgos se realinean y los políticos hacen fila detrás de su líder, de su candidato. Los grupos políticos, como pandillas, alistan las armas para la pelea, hacen cálculos, establecen estrategias. Primero fue la batalla por el gobierno de los partidos mismos, luego vino la definición de las candidaturas y, al final, llegará la campaña por la Presidencia. Resulta agotador. Mientras tanto la sociedad, el ciudadano, observan a esa clase política voraz y aprovechada. Los diputados se aumentan el salario por encima del resto del país. ¿Qué han hecho los diputados para merecer ese premio?, ¿cuántas reformas importantes han legislado?, ¿a qué han llegado además de paralizar los consensos, mostrar una mediocridad expansiva y dejar que los procesos legislativos duerman el sueño de sus intereses de corto plazo?

La inseguridad sigue campante y lo que más preocupa es la misma rivalidad política que ha generado casos terribles como los linchamientos de Tláhuac. Mientras, los políticos se entretienen en sus cálculos sobre 2006.

El 24 de enero de 2005 se llevó a cabo una nueva reunión para presentar otra vez la reforma del Estado. Acudió la clase política, los representantes de los poderes y de los partidos, hubo coincidencia en el discurso, la convocatoria fue amplia, plural, pero el ánimo resultó inversamente proporcional, la estrategia electoral se impone. El convocante Porfirio Muñoz Ledo, a nombre de la Asociación para la Reforma del Estado, marcó la agenda, pero reconoció que: "casi todo se ha dicho" pero "casi nada se ha concretado". Una cosa es el discurso políticamente correcto y otra es la realidad, donde no pasa nada.

¿A quién de la clase política le interesa la reforma de las instituciones? ¿Cuál de los partidos quiere más transparencia, fiscalización, menos recursos, otro mecanismo de acceso a los medios masivos de comunicación? ¿Cómo abrir el espacio reformador cuando la ruta de competencia de 2006 se impone? ¿Qué hacemos con las instituciones? La mejor respuesta de los políticos es especular sobre quiénes serán los 'gallos de la pelea' por la Presidencia. ¿Qué hacer frente al desencanto y las posibilidades de una deserción masiva de las urnas? El país real de 2006 y el país de la reforma del Estado caminan en paralelo, no se tocan, son como dos planetas, cada uno gira en su órbita. Habrá que esperar a 2006 o quizá a 2007 para que se vuelva a reactivar el proceso de las reformas. Quizá la reforma del Estado será como el mito de Sísifo, y a la generación que le toque consolidar la democracia tendrá que subir la piedra de forma permanente durante muchos años.

\section{Democracia paralizada, no reelección}

No pasó mucho tiempo de que la clase política dijera un discurso correcto sobre la necesidad de hacer una reforma del Estado. Dos semanas después, el 10 de febrero, de nueva cuenta otro expediente más se mandó al archivo; la reelección continua de los legisladores chocó contra los intereses de corto plazo de los priistas. ${ }^{4}$ Los senadores que habían aprobado el dictamen, después, simplemente se arrepintieron. Ninguna sorpresa, solamente la certeza de que con este partido y esos legisladores, con la honrosa excepción de un senador tricolor, Genaro Borrego, que mantuvo su voto a favor y defendió el proyecto, el país va hacia una grave regresión política. El resultado fue: 51 votos en contra, 50 a favor y una abstención del pan. Donde los partidos votaron de la siguiente forma: el PRI en contra, el PAN a favor, y el PRD dividió su opinión.

El PRI argumentó que la reelección no resuelve el problema de vínculo entre los poderes; por supuesto no sirve para eso, pero tampoco resuelve el problema de la pobreza ni contribuye a la paz mundial. Que el pueblo no quiere la reelección fue otro argumento; "lo que los ciudadanos queremos es ver a políticos y legisladores que den resultados y sean transparentes, que puedan rendir cuentas". Se dijo en falso que la 
reelección sería para que los intereses económicos estuvieran detrás de los legisladores. Sólo hay que ver a los senadores del PRI que están en contra de la nueva ley de radio y televisión, no únicamente se han ubicado como voceros de los medios, sino que ellos mismos, en varios casos, defienden sus intereses como concesionarios. Nada más falso, la reelección no propicia una infiltración de los intereses económicos, ésta se da por otras vías. Lo que sí propicia la reelección es que los legisladores cuiden a sus electores, porque de ello depende su posibilidad de continuar en el cargo. Pero lo que los priistas confirmaron en ese mal día para las posibilidades democráticas del país, es que no hay manera de modificar los intereses de las cúpulas de los partidos, que no están dispuestas a renunciar a ese territorio de poder.

El 10 de febrero de 2005 se podrá recordar como la fecha en la que el PRI se mostró de 'cuerpo completo', salió su más íntimo sentido político: ser el partido del atraso, el partido que ha atorado la consolidación democrática. Con esa decisión el PRI impidió que México saliera de la extraña condición de ser el único país que no tiene reelección legislativa, salvo Costa Rica, que por cierto sí tiene reelección en los municipios. De forma tramposa también los priistas argumentaron que Costa Rica y México han sido los países más estables. La trampa de nuevo en el argumento. También Arabia Saudita ha sido muy estable bajo la oligarquía que la gobierna. Confunden estabilidad con autoritarismo para el caso mexicano, porque Costa Rica es una vieja democracia en América Latina.

La reelección no es la nueva piedra filosofal, aunque con el nivel de parálisis que tiene el Congreso no hubiera sido un mal resultado empezar por algún lado y romper la inercia de que ningún tema importante y polémico se puede legislar. Claro que lo mejor sería hacer una reforma política completa, o por lo menos una reforma electoral integral, pero esa es una posibilidad muy remota. La reelección legislativa es un mecanismo político que posibilita tener mejores legisladores, con más nivel de conocimiento y profesionalización. Es lamentable que cada tres años lleguen a San Lázaro quinientos nuevos legisladores, de los cuales una mayoría lo hace por primera vez y quizá por única ocasión; que se tarden un año en ubicarse, otro año en entender la tarea de legislar y el último año estén calculando a qué parte del escalafón político se van a ir. Esta improvisación es una pérdida de recursos, capacidades y tiempo.

¿Cómo quieren los senadores del PRI que cambie la pésima percepción que tiene la ciudadanía del Congreso, si lo único que sabe de ellos es que son muy buenos para decir no? ¿Cómo puede mejorar la relación entre el legislador y el votante si se pide el voto una vez en la vida y después no vuelve a haber vinculación? La reelección no resuelve todos los problemas políticos del país y no es el instrumento que cambiará radicalmente al Congreso, pero lo cierto es que puede servir para profesionalizar y para una rendición de cuentas transparente, situaciones que hoy por hoy no existen. Sin reelección el Congreso seguirá sumido en la mediocridad, la improvisación y la falta de profesionalismo. Las fracciones rendirán cuentas a sus jefes partidistas y los ciudadanos seguiremos observando cómo cada tres años, o cada seis años, los diputados y senadores tendrán un desempeño por debajo de cualquier mínimo de calidad.

\section{Los plazos vencidos o la reforma que no fue}

El 30 de junio, 2005, fue la fecha límite para hacer cualquier reforma en materia electoral para las elecciones de 2006; de nuevo no hubo reforma, salvo la del voto de los mexicanos en el extranjero. Hay problemas que se han agravado, como la fiscalización de los gastos partidistas y el modelo de financiamiento y acceso de los partidos a los medios masivos, al mismo tiempo el 
país ha entrado en una suerte de círculo vicioso: los problemas son reales y crecientes y afectan el desempeño de la incipiente democracia, aún así los actores políticos no están dispuestos a pactar ninguna reforma importante.

Los partidos políticos consideran que cualquier cambio hacia una reforma electoral más racional afecta directamente sus intereses estratégicos en la búsqueda de los puestos de elección. El problema es que los partidos son los únicos que pueden cambiar las reglas del juego electoral, por eso las posibilidades de un acuerdo para modificar el actual modelo se vuelven cada vez más remotas.

En mayo de 2005 la Suprema Corte de Justicia de la Nación se pronunció sobre la controversia por el presupuesto de gastos para dicho año, la cual fue presentada en diciembre de 2004 por el poder ejecutivo en contra del poder legislativo - la Cámara de diputados, órgano encargado de aprobar el presupuesto-. La Corte decidió dos asuntos, que el presidente sí tiene la facultad de vetar el presupuesto, decisión que surgió de una apretada votación, seis contra cinco; la otra fue establecer que el presupuesto es de orden administrativo y no una norma general, con lo cual los ministros obligan a los diputados a reconsiderar las observaciones que hizo el ejecutivo.

Esta resolución del máximo tribunal judicial alimentó el ánimo político de los legisladores frente al periodo extraordinario de sesiones del Congreso de la Unión. La única agenda legislativa cierta fue la orden de la Corte para que los diputados atendieran las impugnaciones del presidente de la República.

La necesidad de una reforma electoral era urgente, sobre todo antes de que se iniciaran los procesos internos en los partidos para elegir a sus candidatos, debido a que durante la fase de precampañas no hay ninguna regla para normar estos procesos. La lógica de las precampañas es gastar en medios para lograr una mejor posición en las preferencias electorales.
La posibilidad de una reforma electoral puede plantearse en varios escenarios y con distintos alcances. Los escenarios fueron los siguientes:

Una posibilidad es que decidieran no reforzar los mecanismos y facultades del organismo electoral, no mover nada, en la lógica de no correr ningún riesgo. Desde esta perspectiva, la posibilidad es que no haya reforma porque los partidos no logren llegar a un acuerdo. Lo cual sucedió.

En el caso de que sí se lograra algún tipo de consenso la reforma podría tener una graduación desde una reforma para cubrir el expediente, con un alcance completamente menor, esto es, que no resuelva ninguno de los problemas importantes del actual modelo electoral pero que sí toque algunos como el de mayor capacidad de fiscalización al organismo electoral; o que pueda mover otros temas como las cuotas de género para las candidaturas, uno de los asuntos que con mayor insistencia se propone en los proyectos de reformas electorales en los estados del país.

En la posibilidad de una reforma menor no se tocaría el tema de los medios masivos, en donde los partidos han sido particularmente resistentes. Otro de los rubros que seguramente entraría en la agenda de reforma es el voto de los mexicanos en el extranjero, proyecto que salió con alcances amplios de la Cámara de diputados, pero que los senadores le hicieron fuertes ajustes para dejarlo en un simple voto por correo.

La agenda de una reforma electoral amplia cubre gran cantidad de aspectos: el género en las candidaturas, la composición del poder legislativo con una reducción en el número de legisladores, cambio en la composición entre mayoría relativa y representación proporcional...; de esta manera pasaría por una redefinición de los montos y mecanismos del esquema de financiamiento público que ha crecido por el multiplicador del número de partidos con registro. 
También el dinero público de los partidos tiene que ver con un problema básico: cambiar el acceso a los medios para generar otro modelo de campañas, en donde se menciona como posibilidad el que sea sólo el organismo electoral el responsable del reparto de tiempo en radio y televisión, con lo cual se corta la principal salida de recursos partidistas, que es la contratación directa entre partido y medio. Ésta sería una reforma muy importante, pero tiene pocas posibilidades de salir adelante.

Los partidos, metidos de lleno en su cálculo estratégico para 2006, es decir dinero, dinero y más dinero por el que estar en la televisión la mayor cantidad de tiempo posible, optaron por no mover ni una sola coma de las reglas. Para qué si el modelo funciona y los puestos se pueden "comprar".

\section{Claroscuros en el filo de la evaluación}

La percepción ciudadana es un foco rojo. A finales de abril El Universalpublicó su quinta encuesta nacional sobre la democracia y en esa entrega sobresalieron dos datos interesantes: un crecimiento importante en la percepción de inestabilidad política que pasó de 47\% en abril de 2004 a $62 \%$ en abril de 2005; y un crecimiento en la insatisfacción sobre la democracia que subió de $59 \%$ a $68 \%$ en el mismo periodo. Fue el momento del desafuero a López Obrador. Estos datos se pueden complementar con los que cada año elabora Latinobarómetro, en donde se ve la enorme distancia que existe en América latina, entre una alta aceptación de la democracia y una gran insatisfacción. Otro dato importante en esta encuesta de 2004 es la amenaza a la democracia en México, porque $67 \%$ está de acuerdo en que no le importaría que un gobierno no democrático pudiera llegar al poder, si resuelve los problemas económicos. Estas cifras muestran una cara preocupante de la democracia en México: percepción de inestabilidad, insatisfacción y apoyo a proyectos autoritarios. En este contexto, la sucesión presidencial de 2006 se puede convertir en un gran terreno de oportunidad para proyectos no democráticos. En el Latinobarómetro de 2005 México ocupó el lugar de país más clientelista de América latina, lo cual es otro dato preocupante porque implica una fuerte compra de votos.

¿Cómo puede darse el cambio político en México frente a una parálisis legislativa de los temas estratégicos que pueden consolidar la democracia?

Cuando se habla de cambio se hace referencia a la democracia, entonces hay que mirar, por ejemplo, hacia los espacios de libertad de expresión; lo primero que salta a la vista es que este espacio, que ha costado mucho lograr, no se ha podido traducir en nuevas reglas del juego, en una nueva regulación para la radio y la televisión que pueda estar en sintonía con un proyecto democrático. Una nueva ley de radio y televisión fue otro proyecto bloqueado en el Senado.

Otras áreas del cambio democrático tienen que ver con los espacios de autonomía que se han logrado en la relación entre el Estado y la sociedad, como el arbitraje ciudadano en materia electoral, la política de rendición de cuentas y la transparencia. El modelo de ciudadanización de los organismos electorales se encuentra amenazado y los ejemplos negativos se multiplican por la intención del control partidista.

La rendición de cuentas y la transparencia son proyectos iniciales que se topan con las inercias de opacidad que existen sobre todo en los gobiernos, especialmente en los estados. Hay otros espacios importantes en donde se puede hablar de cambio, como la separación de poderes que fortalece la democracia pero donde los desempeños dejan todavía mucho que desear. 
Los parámetros de evaluación del cambio democrático deben apuntar a preguntas como las que formuló el Instituto Idea: ¿En qué medida el Estado de derecho es efectivo en todo el territorio nacional? ¿Se encuentran los derechos económicos y sociales igualmente garantizados para todos? ¿Dan las elecciones poder a los ciudadanos para ejercer control sobre el gobierno y las políticas públicas? ¿Contribuye el sistema de partidos al buen funcionamiento de la democracia? ¿Rinde el gobierno cuentas de su gestión? ¿Tenemos un mejor sistema de impartición de justicia? ¿Son más confiables los jueces ahora que hace unos años?

Sin duda ha habido cambios en estos años, pero el nivel de fortaleza de la democracia mexicana resulta todavía muy débil, por lo cual las posibilidades de una consolidación están en el aire. Prácticamente se puede ver que todos los cambios que ha habido son reversibles $y$, tal vez, no hacia situaciones radicalmente opuestas sino hacia inercias disfrazadas que mantengan la apariencia de seguir con los cambios, cuando en realidad pueden ser graves retrocesos.

\section{Un presente $\sin$ instrumentos}

Hay momentos en donde los acontecimientos conflictivos se acumulan y tensan el clima político, la mayor parte de 2005 ha tenido este componente. El país está sometido a varias lides que ponen a prueba la capacidad del sistema político para generar gobernabilidad dentro de nuestra recién nacida democracia.

El problema de la parálisis legislativa que hemos vivido durante los últimos años impide generar las nuevas reglas del juego para un proyecto democrático. El hecho de que la clase política haya decidido poner delante sus intereses particulares y dejar de lado los intereses generales del país resulta una carga que cada día se hace más pesada. Sin duda, el mejor laboratorio para observar las jerarquías de los políticos es la agenda de reformas del Congreso de la Unión, ahí podemos ver la precariedad para construir nuevas instituciones.

La falta de un modelo adecuado para garantizar la seguridad y combatir al crimen organizado lleva a los gobiernos a montar operativos de emergencia, así lo hizo Zedillo y ahora Fox repite el esquema. Atravesamos por una situación de emergencia y vemos a un Estado que sale a dar la batalla sin las herramientas necesarias. No hay coordinación entre las policías; existe una amplia impunidad en las fuerzas del orden local; y ya se confunde quién trabaja para el cumplimiento de la ley y quién para el enemigo. Existe una percepción generalizada de que el Estado ha sido rebasado.

Vamos a las elecciones de 2006 prácticamente con las reglas de la última reforma importante, la de 1996. Después de junio de 2005 hubo que decir adiós a la posibilidad de tener un nuevo esquema de equidad en el gasto de los partidos; a un nuevo modelo de acceso de los partidos a los medios masivos para hacer campañas; a una racionalidad que ordene la forma de hacer campaña y modifique el modelo dominante de pura mercadotecnia; también hubo que decirle adiós a los instrumentos necesarios para racionalizar el gasto de los partidos; adiós a calendarios sincronizados para elecciones locales y federales; adiós a una nueva ley de radio y televisión.

La cruzada por un nuevo diseño de las instituciones públicas tendrá que esperar, quizá bastante tiempo. La hipótesis de que cada uno de los tres grandes partidos puede ganar la Presidencia y, por lo tanto, a todos les conviene hacer las reformas es falsa. Cada precandidato piensa, equivocadamente, que si gana no le va a pasar lo mismo que ocurrió en este sexenio. Sin embargo, las señales que hoy existen indican que volveremos a tener un gobierno dividido, de esta manera seguiremos sin ningún instrumento para construir mayorías.

Sólo se han señalado algunas de las reformas que al paso de los meses del año 2005 han quedado en el congelador del Congreso. ¿Cómo será el pago de estas 
facturas a la hora de las elecciones de 2006? ¿Habrá pago o impunidad política? ¿Quién pagará y cuál será el costo?

\section{'Vaciamiento’ político}

Hace cinco años, con el estreno de la alternancia presidencial, era difícil pensar que en un tiempo muy corto llegaríamos a preguntarnos qué hacer frente al cuadro político que han organizado los partidos, los gobiernos y los legisladores.

Las voces de desconcierto y malestar ante nuestra condición democrática se multiplican, mientras tanto los partidos y los precandidatos sólo miran hacia la obtención de dinero para salir en anuncios televisivos. Este proceso de deterioro no cubre sólo a líderes de opinión, se trata de una percepción generalizada: según la encuesta de Latinobarómetro la satisfacción democrática es cada vez más baja, en 2004 sólo 17\% en México dijo estar satisfecho o muy satisfecho con la democracia. El dato es impresionante, pero completamente explicable. En la medición de 2005 la cifra se mantiene. El país muestra las caras deformadas por el crimen organizado y la inseguridad, complementadas con una clase política que ha resultado muy ineficiente, y que ha logrado paralizar cualquier posibilidad de cambio y transformación del sistema político.

La política ha dejado de ser importante como un factor de transformación, o sea, como un generador de expectativas positivas para el futuro inmediato. El empobrecimiento deja un campo político en donde sólo tienen voz y cara los que tienen con qué pagarla. Las campañas políticas se han vuelto una actividad de precandidatos millonarios. El gasto es escandaloso y el vaciamiento de proyectos y contenidos deja un panorama desolador. Mientras las televisoras acumulan dinero político, el organismo electoral hace invitaciones morales a la transparencia, cuando los partidos no quisieron moverle una coma a la legislación en materia de medios, financiamiento y acceso a medios. El gasto de las precampañas ha contabilizado una erogación en radio y televisión de $\$ 885820187$ millones de pesos entre abril y noviembre de 2005 (ElUniversal, 14/XI/2005).

Un comentario se ha generalizado: No hay opciones. Cualquier candidato que quede en los partidos no representa alternativas de futuro, sobre todo porque con las reglas que hoy siguen vigentes la posibilidad de llegar a acuerdos y formar una mayoría que hiciera gobernable la siguiente etapa del país parece una meta completamente inalcanzable. Imaginemos lo que pueden representar otros seis años con una lucha sorda por el poder, que se inicia al día siguiente de que empieza el sexenio, como ocurrió en diciembre del año 2000. Otro gobierno de minoría y parálisis entre 2006 y 2012 es el escenario que se asoma con más probabilidad de realizarse. Gane quien gane la Presidencia tendrá un congreso sin mayoría, dividido en tres facciones y sin incentivos para moverse de su posición y negociar las reformas. Con estos ingredientes no resulta nada atractivo el escenario que se vaticina para 2006.

La política del "todos son iguales", aunque no lo sean, se va generalizado. Cuando los problemas de pobreza, desempleo e inseguridad golpean de forma cotidiana, nuestros políticos se dedican a inventar el pleito o el escándalo de la semana, y los medios a difundirlo.

La política del "no sirve ir a las urnas" es una realidad creciente que expresa la caída de la participación: prácticamente en cualquier elección el porcentaje se ubica por debajo de $50 \%$. Las expectativas de que la democracia electoral pudiera modificar la política y los excesos de la vida económica han desaparecido poco a poco.

La concentración de la riqueza sigue su camino y no hay contrapesos que marquen una tendencia distinta, sólo hay que ver en estos días quiénes serán los nuevos dueños de las líneas aéreas de bajo costo: los mismos que ya controlan las treinta empresas que deciden la economía del país. 
Hoy tenemos un problema grave porque las expectativas para una consolidación democrática declinan. Ya se habla de transiciones fracasadas, y la mexicana puede entrar perfectamente en el 'paquete', lo cual no implica necesariamente rompimientos autoritarios, sino fases de aguda decadencia política en donde el malestar democrático aumente y la insatisfacción con el sistema político genere un mayor desinterés. Evitar la decadencia implicaría un nuevo orden que tuviera en el centro una serie de reformas que hicieran creíbles las posibilidades de que una democracia inicial, como la nuestra, puede transitar a una mejor condición. Desafortunadamente toda la dinámica de 2006 va en sentido contrario.

\section{Notas}

${ }^{1}$ Ponencia presentada en el Coloquio Internacional "Migraciones y Fronteras", 9-11de noviembre de 2005. San Cristóbal de Las Casas, Chiapas.

${ }^{2}$ Respectivamente, Partido Revolucionario Institucional y Partido de la Revolución Democrática.

${ }^{3}$ Actual partido en el gobierno, Partido de Acción Nacional.

${ }^{4}$ Se trata de la reforma constitucional que modifica los artículos 59 y 116 de la Constitución Política de los Estado Unidos Mexicanos, que permitiría la reelección inmediata de diputados federales y locales hasta por tres periodos consecutivos, y la de senadores por una legislatura adicional (EFE, México, 11 de febrero de 2005). 